\title{
A numerical model with varying passive confinement for circular and elliptical concrete-filled steel tubular columns
}

\author{
C. D. Lacuesta ${ }^{a}$, M. L. Romero ${ }^{b}$, A. Lapuebla-Ferri ${ }^{c *}$ and J. M. Adam ${ }^{b}$ \\ aUniversitat Politècnica de València. Valencia, Spain. \\ bICITECH, Universitat Politècnica de València. Valencia, Spain. \\ ${ }^{\mathrm{c}}$ Department of Continuum Mechanics and Theory of Structures. Universitat Politècnica de València. \\ Valencia, Spain \\ *corresponding author, e-mail address: anlafer0@mes.upv.es
}

\begin{abstract}
In this work, a non-linear 3D numerical model to study concrete-filled tubular (CFST) columns is presented. The numerical model is capable to consider the passive confinement that occurs in the concrete core of CFST columns, under which an increase in the strength and ductility of the element is expected. Passive confinement is governed by the volumetric deformation of the concrete core and by the increment of concrete strength, so it was necessary to define both aspects in the constitutive model. In the volumetric deformation, the elastic and plastic components were included, the latter by using the Drucker-Prager model. Different values for the angle of dilatancy were defined for normal and high strength concrete. The model was validated by using experimental tests performed on stub columns and eccentrically loaded columns. In addition, different section geometries were tested. According to the results, the model was able to describe the non-uniform confinement that appears in the concrete core of CFST columns.
\end{abstract}

Keywords: Passive confinement; concrete-filled tubular columns; high-strength concrete; buckling; finite element analysis.

\section{Introduction}

Composite behavior of CFST columns can be understood through the interaction between the concrete core and the steel tube. When compressive loads are applied, transverse strains appears in the concrete due to Poisson's effect: the concrete core expands laterally while the steel section tends to avoid it. This phenomenon is known as concrete confinement.

A consequence of concrete confinement is an increment in the bearing capacity of the concrete and, by contrast, a reduction in the steel tube capacity. Altogether, this composite behavior produces higher failure loads than the sum of the failure loads of concrete and steel taken separately.

Nowadays two mechanisms can explain the aforementioned increment in the bearing capacity of a CFST column: active confinement and passive confinement. The first one happens when a lateral pressure is applied constantly and it is not changed in terms of axial or lateral strain. On the other hand, passive confinement is produced when the lateral pressure on the concrete varies in terms of deformation; hence, a tri-axial stress state appears in the concrete while a bi-axial stress state appears in the steel.

It is worth noting that a very specific type of confinement appears in CFST columns. For the initial stages of deformation, the steel Poisson's coefficient $\left(v_{s} \approx 0.3\right)$ is higher than the concrete one $\left(v_{s} \approx 0.2\right)$, so the lateral deformations that appear in both materials are higher in the steel tube. According to this, there is no confinement effect in the concrete core at initial stages. However, the lateral strain of the concrete core does not only depend on its elastic coefficient but also on its plastic behavior. According to Johansson [1], concrete plastification begins approximately at the $50 \%$ of its maximum compressive strain, so the lateral strain significantly increases until failure occurs. Moreover, since lateral strains increase faster in 
concrete than in steel, concrete core reaches the steel tube at given moment during its plastification process, marking the initiation of the passive confinement mechanism.

Understanding and modelling passive confinement of concrete core in CFST is a challenging task. Different researchers have proposed material models, although the confinement level of the concrete core is measured in only a few works, such as the experimental setups performed by Cetisli and Naito [2] [3]. In addition, when passive confinement appears, stress-strain relationships that appear in the literature are defined from geometric parameters: $D / t, L / D$, etc. [4]. Moreover, since lateral deformations depend on concrete strength, a different behavior is expected between normal and high-strength concrete (NSC and HSC, respectively) in terms of passive confinement. While it is interesting to quantify the amount of concrete confinement since this phenomenon is directly related with structural ductility, the influence of each concrete type on it remains unclear. Gourley and co-workers [5] affirmed that the use of HSC produced less confinement effect compared to NSC, but on the contrary, other authors such as Zegiche and Chaoui [6] argued otherwise: it is possible to obtain a ductile response if HSC is used, but only if higher thicknesses of steel tubes are employed. The less ductile response of HSC seems to be related to its low lateral strain when it is compared with NSC. The influence of HSC in the concrete confinement in columns has been previously studied [7][8]. Finally, in previous works involving finite element (FE) simulations, several parameters that govern confinement are usually taken as constants, such as friction angle, $K$-ratio and dilatancy angle. This variation was considered by few authors, such as $\mathrm{Yu}$ et al. [9].

In this paper, a numerical model is proposed to simulate the mechanism of varying passive confinement of the concrete core in CFST columns. The influence of several parameters is taken into consideration, such as the crosssection shape (circular and elliptical), load eccentricity and slenderness. The proposed model was calibrated through both experimental tests previously carried out by the authors and others found in the literature. As a result, a particular definition of the stress-strain curve and the dilatancy angle are provided, taken into account that both of them vary with lateral pressure.

\section{Numerical modelling}

ABAQUS [10] software was used to simulate the mechanical behavior of CFST columns. According to the features of these elements, material models for steel and concrete were defined separately and assigned to the corresponding regions of the model along with their interactions and boundary conditions.

\subsection{Model geometry}

Model geometry included three parts: loading plate, concrete core and steel tube (Fig. 1). As the test specimens presented two symmetry planes, the model geometry was reduced to $1 / 4$, as it was done by $\mathrm{Hu}$ et al. [4]. The boundary conditions applied to the model considered the simplification of the model caused by the assumption of double symmetry (Fig. 2). A three-dimensional, cubic finite element with linear approximation and full integration (C3D8) was adopted for the mesh.

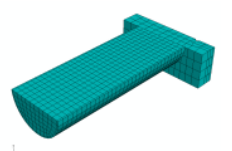

(a)

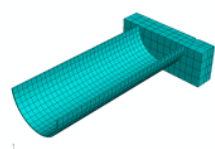

(b)

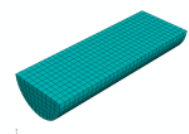

(c)
Fig. 1. Components of model geometry: (a) full model; (b) model without concrete core and (c) concrete core.

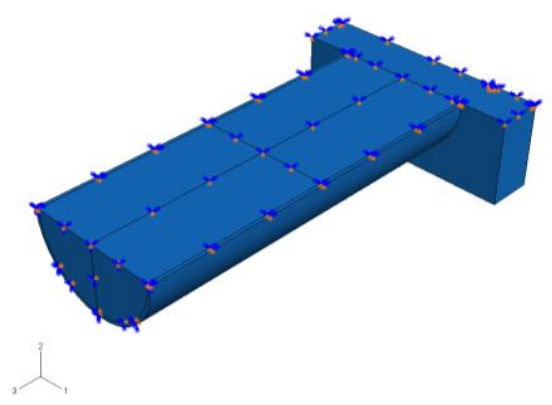

Fig. 2. Boundary conditions in the FE model.

\subsection{Surface interactions}

The interactions between the components of the model were defined by using surfaces. The interaction between the steel tube and the endplates was treated like a "tie contact". The frictional model of Mohr-Coulomb was considered to simulate the concrete core-tube interaction, with a friction coefficient of 0.25 , as it was adopted previously by $\mathrm{Hu}$ et al. [4]. 


\subsection{Steel model}

Steel behaves initially as an elastic material, so the following values were adopted for its elastic constants: $E_{s}=210 \mathrm{GPa}$ for the elasticity modulus and $v_{s}=0.3$ for the Poisson's ratio. Steel in ABAQUS was treated as elastic up to its yield strength and as plastic from that point to the final strain. Von Mises plastification criterion was adopted.

\subsection{Concrete model}

Concrete elastic behavior is defined through the elasticity modulus $E_{c}$ as a function of the concrete strength $f_{c}$ - see Eq. (1) - and a Poisson's ratio $v_{c}=0.2$.

$$
E_{c}=4700 \cdot \sqrt{f_{c}}
$$

To simulate the variable confinement of the concrete core, the Extended Drucker-Prager model was considered, following the work presented by Hu et al. [4]. This model allows not only an adequate characterization of concrete, but also elevated control possibilities to simulate a variable concrete confinement.

A number of parameters are necessary in order to define adequately the surface of plastic fluency prescribed by Drucker-Prager in a stress space. First, it was adopted an internal frictional angle $\beta=20^{\circ}$, as it was also done by $\mathrm{Hu}$ et al. [4]. Secondly, for the ratio of biaxial and triaxial ultimate stresses it was adopted $K=0.778$.

Finally, a special attention is put into dilatancy, this is, the increase of the material volume when it is subjected to shear stresses. Drucker-Prager model was considered in order to choose a plastic flow potential - Eq. (2) independent of the yield surface that permitted the calculation of lateral plastic deformations.

$$
F=t-p \cdot \tan \psi
$$

where $\psi$ is the angle of dilatancy, which can be defined through Eq. (3):

$$
\psi=-\frac{\sqrt{3}}{6} \cdot \frac{\mathrm{d} \varepsilon_{1}^{p}+2 \cdot \mathrm{d} \varepsilon_{2}^{p}}{\mathrm{~d} \varepsilon_{1}^{p}-\mathrm{d} \varepsilon_{2}^{p}}=-\frac{1}{6} \cdot \frac{\mathrm{d} I_{1}^{\prime p}}{\sqrt{\mathrm{d} J_{2}^{\prime p}}}
$$

The greater the angle of dilatancy, the greater the plastic lateral deformations $\varepsilon_{p 2}$ and $\varepsilon_{p 3}$ that appear in the concrete core for the same plastic longitudinal deformation $\varepsilon_{p l}$. As was said before, lateral deformations are directly related with concrete confinement.

\section{Variable passive confinement for concrete model}

\subsection{Concrete damage in CFST columns}

A main aspect that characterizes the response of a CFST column is the lateral strain exerted by the steel tube on the concrete core. This strain appears from the beginning of the loading process (elastic behavior) to the very failure (plastic behavior).

The high non-linearity of the stress-strain curve is the result of a failure mechanism that occurs inside the concrete core. There can be found differences between NSC and HSC. In this last case, cracks are unstable and the concrete element can break in a brittle, explosive way. Nevertheless, when concrete is used in CFST columns the process of failure is conditioned by the confinement effect.

When an axial load is applied in low slenderness columns, concrete and steel deform longitudinally and transversally. Since the initial Poisson's coefficient of the steel is greater than the coefficient of the concrete core, there is no transmission of loads between steel and concrete at low strain levels. When the elasto-plastic regime begins, microcracks appear in the concrete, causing a lateral expansion faster than the lateral expansion of steel. Concrete core finally reaches the steel tube and the confinement begins, developing a triaxial stress state in the concrete core and a biaxial stress state in the steel tube. The resulting confining pressures are not constant, but they increase as the lateral strains of the concrete also does. This behavior ends when plastification of the confining system occurs, and the confining pressure remains constant until concrete breaks.

\subsection{Variable dilatancy model}

In the elastic range, lateral strains are governed by the Poisson's coefficient. When the plastic range is reached plastic lateral deformations also appear, whose quantification is needed to develop a concrete model that includes the effect of confinement. According to Eq. (3), plastic lateral deformations are governed by dilatancy angle. Lokuge et al. [11] showed that during a compression test of a concrete specimen, the volumetric deformation turned to zero when the maximum stress corresponding to the concrete strength $f_{c}$ was reached, so concrete volume returned to the value before loading 
process started. This phenomenon was observed for NSC and HSC in the work of Papanikolaou and Kappos [12], so the dilatancy angle could be computed for each type of concrete as a function of the concrete strength and the confinement pressure $f_{l}$. Fig. 3 depicts the procedure that was employed to obtain the dilatancy angles for a concrete strength of $30 \mathrm{MPa}$.

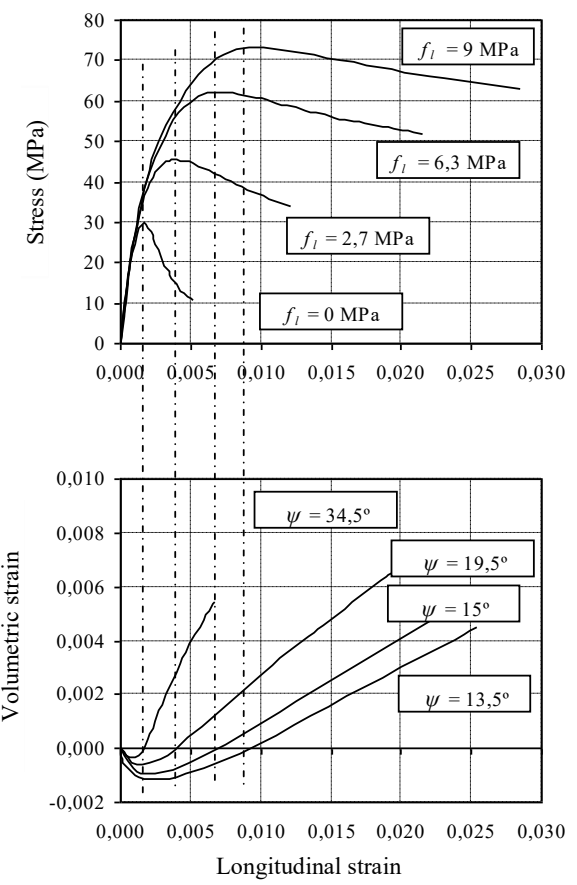

Fig. 3. Volumetric deformation for a concrete with $f_{c}$ $=30 \mathrm{MPa}$, considering different values for confinement pressure $\psi$.

On the other hand, Table 1 shows the results for dilatancy angle $\psi^{0}$ that turns the volumetric deformation to zero when stress is equal to $f_{c}$ for low, medium and high strength concretes $(30,60$ and $90 \mathrm{MPa}$, respectively) and for different values for confinement pressure $f_{l}$.

Table 1. Values for confinement pressure and dilatancy angle.

\begin{tabular}{cccccc}
\hline \multicolumn{2}{c}{$\mathbf{3 0} \mathrm{MPa}$} & \multicolumn{2}{c}{$\mathbf{6 0} \mathrm{MPa}$} & \multicolumn{2}{c}{$\mathbf{9 0} \mathrm{MPa}$} \\
\hline $\begin{array}{c}\boldsymbol{f}_{\boldsymbol{i}} \\
(\mathrm{MPa})\end{array}$ & $\boldsymbol{\psi}^{\boldsymbol{o}}$ & $\begin{array}{c}\boldsymbol{f}_{\boldsymbol{i}} \\
(\mathrm{MPa})\end{array}$ & $\boldsymbol{\psi}^{\boldsymbol{o}}$ & $\begin{array}{c}\boldsymbol{f} \boldsymbol{i} \\
(\mathrm{MPa})\end{array}$ & $\boldsymbol{\psi}^{\boldsymbol{o}}$ \\
\hline 0.0 & 34.5 & 0.0 & 41.0 & 0.0 & 47.0 \\
2.7 & 19.5 & 5.4 & 27.0 & 6.7 & 35.5 \\
6.3 & 15.0 & 12.6 & 20.5 & 15.7 & 28.0 \\
9.0 & 13.5 & 18.0 & 18.5 & 22.5 & 25.0 \\
\hline
\end{tabular}

It is observed that when lateral confinement pressure increases, dilatation angle decreases. As the dilatancy angle regulates the lateral plastic deformations of the concrete core, it seems logical to think that the greater the lateral pressure of confinement is applied, the smaller will be the lateral deformations that occur in the concrete core and, therefore, lower dilatancy angles are obtained.

\subsection{Variable stress-strain relationships}

In this section, stress-strain curves are developed for a given concrete strength and the maximum confining pressure that occurs for passive confinement. To this end, the model parameters were calibrated considering the results of experimental settings that were performed in previous works.

Eq. (4) relates concrete compressive strength $f_{c}$ with confined concrete compressive strength $f_{c c}$ and lateral confinement pressure $f_{l}$ :

$$
f_{c c}=f_{c}+k_{1} \cdot f_{l}
$$

Besides, Eq. (5) relates concrete maximum strain $\varepsilon_{c}$ with confined concrete maximum strain $\varepsilon_{c c}$ :

$$
\varepsilon_{c c}=\varepsilon_{c} \cdot\left(1+k_{2} \cdot \frac{f_{l}}{f_{c}}\right)
$$

The characterization of the stress-strain curves for confined concrete followed the model proposed by Hu et al. [4] (Fig. 4).

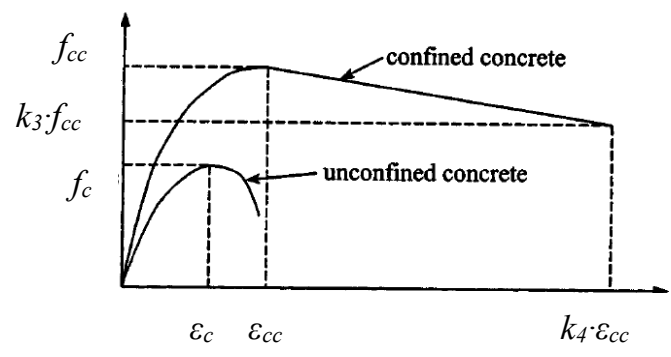

Fig. 4. Stress-strain curves for confined and unconfined concrete.

For the ascending branch of the stress-strain curve, Eq. (6) was adopted from Saenz [13]:

$$
f_{c}=\frac{E_{c} \cdot \varepsilon_{c}}{1+\left(R+R_{E}-2\right) \cdot\left(\frac{\varepsilon_{c}}{\varepsilon_{c c}}\right)-(2 \cdot R-1) \cdot\left(\frac{\varepsilon_{c}}{\varepsilon_{c c}}\right)^{2}+R \cdot\left(\frac{\varepsilon_{c}}{\varepsilon_{c c}}\right)^{3}}
$$

where:

$$
R=\frac{R_{E} \cdot\left(R_{\sigma}-1\right)}{\left(R_{\varepsilon}-1\right)^{2}}-\frac{1}{R_{E}}
$$




$$
R_{E}=\frac{E_{c} \cdot \varepsilon_{c c}}{f_{c c}}
$$

According to $\mathrm{Hu}$ et al. [4], $R_{\sigma}=R_{\varepsilon}=4$ for the sake of simplification. For the descending branch of the stress-strain curve of the confined concrete (Fig. 4), constants $k_{3}$ and $k_{4}$ characterize the ending point of the line that models the softening behavior. It can be taken $k_{4}=11$. On the other hand, constant $k_{3}$ along with $k_{l}$ in Eq. (4) are related to the values of the maximum strength of confined concrete and its residual strength, and they must be obtained experimentally by calibration with the experimental setups detailed in the following subsection.

\subsection{Experimental data and calibration results}

Data from experimental settings were taken from literature (Table 2). 12 stub columns were chosen, with a ratio $L / D \approx 3$ in order to avoid second order effects, thus guaranteeing a sectional behavior. In addition, these tests covered a wide range of variables (concrete strength $f_{c}$, steel strength $f_{y}$ and ratio diameter-to thickness $D / t$ ) for low slendernesses and centered loads.

Table 2.Mechanical and geometrical features of the experimental setups used to calibrate stress-strain curves.

\begin{tabular}{lccccc}
\hline Reference & $\begin{array}{c}\boldsymbol{f}_{\boldsymbol{c}} \\
(\mathrm{MPa})\end{array}$ & $\begin{array}{c}\boldsymbol{f}_{\boldsymbol{y}} \\
(\mathrm{MPa})\end{array}$ & $\boldsymbol{D} / \boldsymbol{t}$ & $\boldsymbol{L} / \boldsymbol{D}$ & $\boldsymbol{\lambda}$ \\
\hline $\begin{array}{l}\text { Schneider, 1998 } \\
\text { [14] }\end{array}$ & 27.2 & 232 & 100.00 & 3.00 & 0.13 \\
Huang et al., & 31.2 & 273 & 70.00 & 3.00 & 0.14 \\
2002 [15] & & & & & \\
Giakoumelis and & 27.8 & 365 & 23.40 & 2.62 & 0.13 \\
Lam, 2004 [16] & 46.1 & 365 & 22.91 & 2.61 & 0.13 \\
& 79.1 & 343 & 29.83 & 2.62 & 0.14 \\
& 41.1 & 279 & 101.35 & 3.00 & 0.16 \\
Sakino et al., & 77.0 & 853 & 16.69 & 3.00 & 0.21 \\
2004 [17] & 85.1 & 823 & 52.09 & 3.00 & 0.21 \\
& 38.5 & 350 & 46.11 & 2.97 & 0.15 \\
Yu et al., 2007 & 42.8 & 350 & 60.00 & 3.09 & 0.16 \\
[18] & 47.7 & 350 & 45.82 & 2.97 & 0.15 \\
& 78.7 & 350 & 60.44 & 3.09 & 0.18 \\
\hline
\end{tabular}

Table 3 shows the results of the constants $k_{I}$ and $k_{3}$ and the lateral confinement pressure $f_{l}$, measured in the center of concrete core.

Table 3. Calibration values of the parameters that govern stress-strain curves.

\begin{tabular}{lccc}
\hline Reference & $\boldsymbol{k}_{\boldsymbol{l}}$ & $\boldsymbol{k}_{3}$ & $\begin{array}{c}\boldsymbol{f}_{\boldsymbol{l}} \\
(\mathrm{MPa})\end{array}$ \\
\hline Schneider, 1998 [14] & 2.80 & 0.60 & 1.96 \\
Huang et al., 2002 [15] & 3.00 & 0.62 & 3.14 \\
Giakoumelis and Lam, & 2.00 & 0.60 & 17.60 \\
2004 [16] & 4.00 & 0.80 & 13.40 \\
& 4.00 & 0.90 & 9.87 \\
Sakino et al., 2004 [17] & 1.50 & 0.50 & 18.70 \\
& 1.50 & 0.55 & 45.07 \\
& 2.00 & 0.55 & 1.93 \\
Yu et al., 2007 [18] & 1.50 & 0.55 & 7.80 \\
& 3.50 & 0.75 & 5.70 \\
& 4.00 & 0.60 & 3.73 \\
& 4.00 & 0.62 & 6.87 \\
\hline
\end{tabular}

Fig. 5 and Fig. 6 depict the values that define the stress-strain curve. In Fig. 5 it can be observed that for low and medium concrete strength the value of $k_{1}$ rises with the confinement pressure, reaching a peak value of and 4 and remaining constant even if $f_{l}$ rises. This trend is not observed in $\mathrm{HSC}$, and $\mathrm{k} 1=1.5$ independently of $f_{l}$.

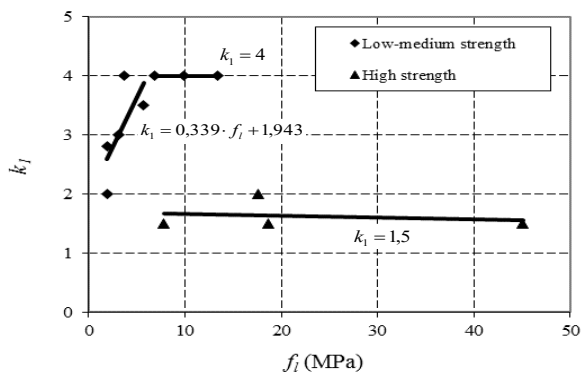

Fig. J. Fitting of parameter $k_{l}$.

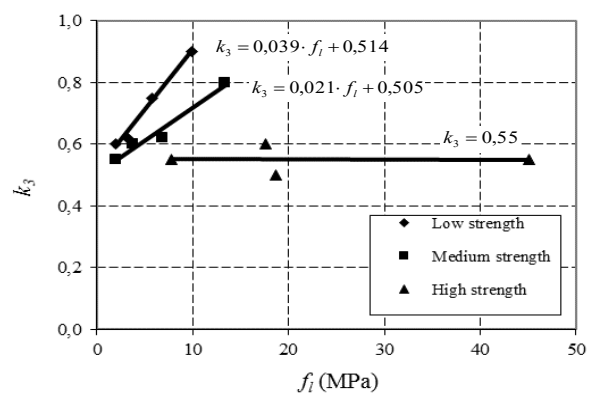

Fig. 6. Fitting of parameter $k_{3}$. 
It can be also observed (Fig. 6) that the variation of $k_{3}$ with the confinement is more accused for NSC than for HSC. This result fits with what was observed by previous authors like Attard and Setunge [19][19]. A rise in the concrete strength by confinement effect is less pronounced as the concrete strength increases.

\section{Verification of the numerical model}

\subsection{Experimental setups}

The numerical model was verified with the experimental tests found in the literature for different column geometries (Table 4).

Table 4. Values for cylindrical stub columns with centered loads.

\begin{tabular}{|c|c|c|c|c|c|c|c|}
\hline Group & Reference & $\begin{array}{c}\boldsymbol{D} \\
(\mathrm{mm})\end{array}$ & $\begin{array}{c}\boldsymbol{t} \\
(\mathrm{mm})\end{array}$ & $\begin{array}{c}\boldsymbol{L} \\
(\mathrm{mm})\end{array}$ & $\begin{array}{c}\boldsymbol{e} \\
(\mathrm{mm})\end{array}$ & $\begin{array}{c}f_{c} \\
(\mathrm{MPa})\end{array}$ & $\begin{array}{c}\boldsymbol{f}_{\boldsymbol{y}} \\
(\mathrm{MPa})\end{array}$ \\
\hline \multirow{14}{*}{$\begin{array}{l}\text { Circular } \\
\text { stub } \\
\boldsymbol{e}=0\end{array}$} & Gardner, 1968 [20] & $168-169$ & $2.6-3.6$ & 305 & 0 & $27.0-37.1$ & $288-338$ \\
\hline & $\begin{array}{l}\text { Tomii and Yoshimaro, } 1977 \\
\text { [21] }\end{array}$ & 152 & $2.0-3.0$ & $457-610$ & 0 & $24.1-28.9$ & $338-290$ \\
\hline & Cai and Jiao, 1984 [22] & 166 & 5.0 & $350-660$ & 0 & 29.6 & 274 \\
\hline & Schneider, 1998 [14] & 140 & $3.0-6.5$ & 602 & 0 & $23.8-28.2$ & $285-313$ \\
\hline & Saisho et al., 1999 [23] & 140 & 2.4 & 419 & 0 & 70.2 & 463 \\
\hline & $\begin{array}{l}\text { O'Shea and Bridge, } 2000 \\
{[24]}\end{array}$ & 165 & 2.8 & 581 & 0 & 80.2 & 363 \\
\hline & Huang et al., 2002 [15] & $200-300$ & $2.0-5.0$ & $600-900$ & 0 & 27.0 & $266-342$ \\
\hline & $\begin{array}{l}\text { Giakoumelis and Lam, } 2004 \\
\text { [16] }\end{array}$ & 115 & $3.8-4.0$ & 300 & 0 & $25.1-74.9$ & 343 \\
\hline & Sakino et al., 2004 [17] & $122-149$ & $3.0-4.5$ & $366-1350$ & 0 & $40.5-77.0$ & $279-576$ \\
\hline & Zhang and Wang, 2004 [25] & 133 & 5.4 & 397 & 0 & 73.2 & 392 \\
\hline & Han et al., 2005 [26] & $60-250$ & $1.9-2.0$ & $180-750$ & 0 & $88.1-93.6$ & $282-404$ \\
\hline & Yu et al., 2007 [18] & $165-219$ & $2.7-4.7$ & $510-650$ & 0 & $47.7-55.3$ & 350 \\
\hline & Gupta et al., 2007 [27] & 89 & 2.7 & 340 & 0 & 29.7 & 360 \\
\hline & Han et al. 2008 [28] & 206 & 2.8 & 600 & 0 & 75.4 & 363 \\
\hline $\begin{array}{l}\text { Circular } \\
\text { stub } \\
\boldsymbol{e} \neq 0\end{array}$ & Lee et al., 2011 [29] & $240-480$ & $6-12$ & $720-1.800$ & $60-300$ & $31.5-59$ & $468-517$ \\
\hline \multirow{8}{*}{$\begin{array}{l}\text { Circular } \\
\text { slender }\end{array}$} & $\begin{array}{l}\text { Gardner and Jacobson, } 1967 \\
\text { [30] }\end{array}$ & 102 & 3.07 & 1542 & 0 & 34.7 & 614 \\
\hline & $\begin{array}{l}\text { Knowles and Park, } 1969 \\
\text { [31] }\end{array}$ & 83 & $1.4-5.84$ & $1118-1422$ & 0 & 41.5 & $406-490$ \\
\hline & Zhong and Wang, 1978 [32] & 108 & 4 & 1620 & 0 & 34.1 & 351 \\
\hline & Pan and Liang, 1988 [33] & 160 & 4.5 & 2420 & 0 & 43.3 & 318 \\
\hline & Gu et al., 1993 [34] & 169 & 7.5 & 1768 & 0 & 70.8 & 360 \\
\hline & Matsui et al., 1995 [35] & 165 & 4.17 & 1982 & 0 & 40.92 & 359 \\
\hline & $\begin{array}{l}\text { Zeghiche and Chaoui, } 2005 \\
\text { [6] }\end{array}$ & 160 & $4.98-5.03$ & $2000-3000$ & 0 & $40-99$ & $270-283$ \\
\hline & De Nardin et al., 2007 [36] & 127 & $3.2-4.85$ & 1200 & 0 & $46-58$ & $329-355$ \\
\hline \multirow{4}{*}{$\begin{array}{l}\text { Circular } \\
\text { slender }\end{array}$} & $\begin{array}{l}\text { Kilpatrik and Rangan, } 1999 \\
\text { [37] }\end{array}$ & 76 & 2.2 & $802-2402$ & $15-50$ & 56.79 & $410-435$ \\
\hline & $\begin{array}{l}\text { Zeghiche and Chaoui, } 2005 \\
\text { [6] }\end{array}$ & 160 & 5 & $2000-4000$ & $8-32$ & 100 & $271-281$ \\
\hline & Rangan and Joice, 1992 [38] & 102 & 1.6 & $1313-2323$ & $10-30$ & 67.4 & 218 \\
\hline & Portolés et al., 2011 [39] & 100 & $3-5$ & $2000-3000$ & $20-50$ & $30-96$ & $340-360$ \\
\hline
\end{tabular}




\subsection{Comparison between the experimental data and $F E$ analysis}

Fig. 7depicts the comparison of the experimental results of one of the cases with the results of the numerical model.

In the following, it was compared the maximum load obtained in the experimental setup $P_{u, E X P}$ with the maximum load obtained in the numerical model $P_{u, N U M}$. For this reason, the parameter $\xi$ was introduced:

$\xi=\frac{P_{u, E X P}}{P_{u, N U M}}$

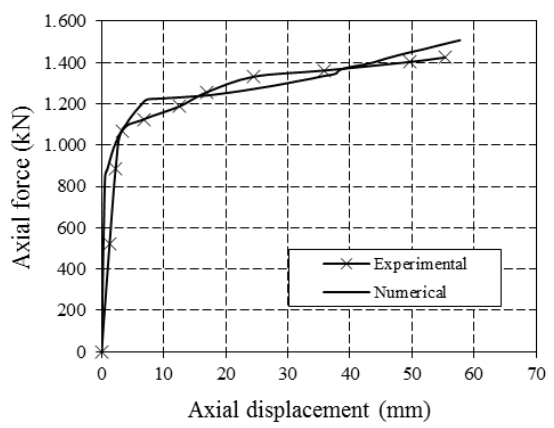

Fig. 7. Axial force-displacement/strain experimental versus numerical curves.

Table 5 shows the average values of $\xi$ for the cylindrical columns as a function of the strength of the concrete core and the slenderness $\lambda$ and the eccentricity $e$ of the column.

Table 5. Comparative table.

\begin{tabular}{lcc}
\hline \multirow{2}{*}{$\begin{array}{l}\text { Circular } \\
\text { section }\end{array}$} & \multicolumn{2}{c}{$\xi$} \\
\cline { 2 - 3 } & $<50 \mathrm{MPa}$ & $>50 \mathrm{MPa}$ \\
\hline $\boldsymbol{e}=0, \lambda<0.2$ & 1.01 & 0.96 \\
$\boldsymbol{e}=0, \lambda \geq 0.2$ & 1.06 & 1.04 \\
$\boldsymbol{e} \neq 0, \lambda<0.2$ & 0.99 & 0.83 \\
$\boldsymbol{e} \neq 0, \lambda \geq 0.2$ & 1.00 & 0.98 \\
\hline
\end{tabular}

Fig. 8 depicts the ranges of the parameter $\xi$ in circular columns. Fig. 9 depicts the comparison of the results.

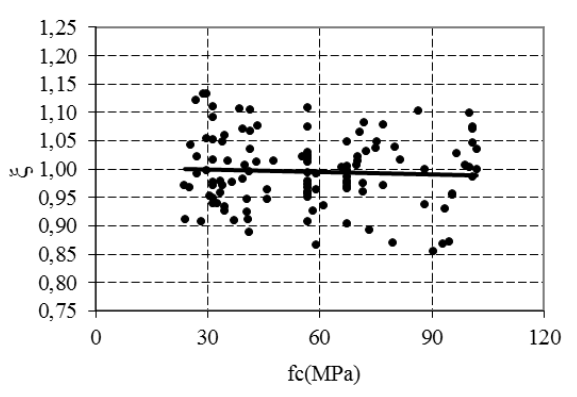

Fig. 8. Validation results.

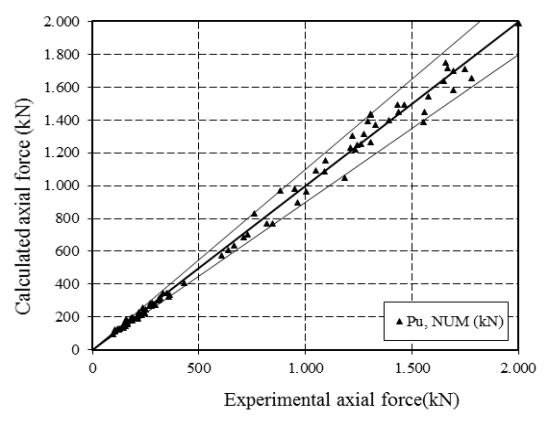

Fig. 9. Comparison of the results.

\section{Conclusions}

From the analyzed cases, it is concluded that only for those columns with relatively low values of slenderness and without eccentricity mostly centered stub columns - an acceptable confinement is produced and a significantly increase of resistance appears.

In the rest of the circular cases (slender centered, stub eccentric and slender eccentric columns), there is no appreciable confinement, so the overall strength of the column is not increased. In all the eccentric cases analyzed, the applied eccentricity is at least $10 \%$ of the diameter. The slenderness of the slender centered cases is in most cases greater than 0.5. It is recalled here that the EC4 eliminates any contribution of the confinement to the resistance when the eccentricity exceeds $10 \%$ of the diameter or the slenderness is greater than 0.5 , so no confinement is appreciated in these cases in the numerical model.

Except in the case of the stub-and-centered columns, it is observed that even if no confinement occurs and consequently the overall resistance of the column does not increase, the ductility is improved.

When comparing the ratios of the developed numerical model, it can be concluded that it is valid for a wide range of cases. This model helps 
to understand the behavior of CFST columns with HSC. In addition, the numerical model approximates the structural response of the CFST columns with HSC. This suggests that the application of the methodology described in this work enables the development of further studies in different CFST columns filled with HSC.

\section{References}

[1] Johansson M. The Efficiency of passive confinement in CFT Columns. Steel and Composite Structures 2002; 2: 379-96.

[2] Cetisli F, Naito CJ. Concrete subjected to varying confinement, II: modeling. Journal of Advanced Concrete Technology 2009; 7: 239249.

[3] Cetisli F, Naito CJ. Concrete subjected to varying confinement, I: experimental evaluation. Journal of Advanced Concrete Technology 2009; 7: 251-261.

[4] Hu HT, Huang CS, Wu MH, Wu YM. Nonlinear analysis of axially loaded concrete filled tube columns with confinement effect. Journal Structures Engineering, ASCE 2003; 129: 1322 1329.

[5] Gourley BC, Tort C, Hajjar JF, Schiller PH. A Synopsis of Studies of the Monotonic and Cyclic Behavior of Concrete-Filled Steel Tube BeamColumns. Structural Engineering Report No. ST01-4; 2001.

[6] Zeghiche J, Chaoui K. An experimental behaviour of concrete-filled steel tubular columns. Journal of Constructional Steel Research 2005; 61: 53-66.

[7] Liu DL, Gho WM, Yuan H. Ultimate capacity of high-strength rectangular concrete-filled steel hollow section stub columns. Journal of Constructional Steel Research 2003; 12: 14991515.

[8] Hernández-Figueirido D, Romero ML, Bonet JL, Montalvá JM. Ultimate capacity of rectangular concrete-filled steel tubular columns under unequal load eccentricities. Journal of Constructional Steel Research 2012; 68: 107117.

[9] Yu T, Teng JG, Wong YL, Dong SL. Finite element modelling of confined concrete-I: Drucker-Prager type plasticity model. Engineering Structures 2010; 32: 665-679.

[10]ABAQUS Analysis user's manual, ABAQUS Theory manual. Documentation Version 6.1.

[11]Lokuge WP, Sanjayan JG, Setunge S. Stressstrain model for laterally confined concrete. Journal of Materials in Civil Engineering, ASCE 2005; 17(6).
[12] Papanikolaou VK, Kappos AJ. Confinementsensitive plasticity constitutive model for concrete in triaxial compression. International Journal of Solids and Structures 2007; 44(21): 7021-7048.

[13] Saenz, LP. Discussion of equation for the stressstrain curve of concrete by P. Desayi and S. Krishnan. ACI Structural Journal 1964; 61: 1229-1235.

[14] Schneider SP. Axially loaded concrete-filled steel tubes. Journal of Structural Engineering ASCE 1998; 124(10): 1125-1138.

[15]Huang CS, Yeh YK, Liu GY, Hu HT, Tsai KC, Weng YT, Wang SH, Wu MH. Axial load behaviour of stiffened concrete-filled steel columns. Journal of Structural Engineering 2002; 128(9): 1222-1230.

[16] Giakoumelis G, Lam D. Axial capacity of circular concrete-filled tube columns. Journal of Constructional Steel Research 2004; 60: 10491068.

[17] Sakino K, Nakahara H, Morino S, Nishiyama I. Behavior of centrally loaded concrete-filled steel-tube short columns Journal of Structural Engineering ASCE 2004; 130(2): 180-188.

[18] Yu Z-W, Dim F-X, Cai CS. Experimental behavior of circular concrete-filled steel tube stub columns. Journal of Constructional Steel Research 2007; 63: 165-174.

[19] Attard MM, Setunge S. Stress-strain relationship of confined and unconfined concrete. ACI Materials Journal 1996; 93: 432-442.

[20] Gardner NJ. Use of spiral welded steel tubes in pipe columns. Journal of the American Concrete Institute 1968; 65(11): 937-942.

[21] Tomii M, Yoshimaro K. Experimental studies on concrete-filled steel tubular columns under concentric loading. International Colloquium on Stability of Structures under Static and Dynamic Loads, 1977. Washington, D.C. May 17-19, 718-741.

[22] Cai SH, Jiao ZS. Behavior and ultimate strength of short concrete-filled steel tubular columns (in Chinese). Journal of Building Structures 1984; 6 : 13-29.

[23] Saisho AT, Nakaya K. Ultimate bending strength of high-strength concrete-filled steel tube columns (in Japanese). Journal of Structural and Construction Engineering 1999; 523: 133-40.

[24] O'Shea MD, Bridge RQ. Design of circular thinwalled concrete filled steel tubes. Journal of structural engineering ASCE 2000; 126(11): 1295-1303.

[25]Zhang S, Wang Y. Failure modes of short columns of high-strength concrete filled steel tubes (in Chinese). China Civil Engineering Journal 2004; 37(9): 1-10. 
[26]Han LH, Yao GF, Zhao XL. Experiment behavior of thin-walled hollow structural steel (HSS) stub columns filled with selfconsolidating concrete (SCC). Journal of Constructional Steel Research 2005; 61(9): 1241-69.

[27] Gupta PK, Sarda SM, Kumar MS. Experimental and computational study of concrete-filled steel tubular columns under axial loads. Journal of Constructional Steel Research 2007; 63: 182193.

[28] Han L-H, Liu W, Yang Y-F. Behaviour of concrete-filled steel tubular stub columns subjected to axially local compression. Journal of Constructional Steel Research 2008; 64: 377387.

[29]Lee S-H, Uy B, Kim S-H, Choi Y-H, Choi S-M. Behavior of high-strength circular concrete-filled steel tubular (CFST) column under eccentric loading. Journal of Constructional Steel Research 2011; 67: 1-13.

[30] Gardner NJ, Jacobson ER. Structural behavior of concrete-filled steel tubes. Journal of the American Concrete Institute 1967; 64(11): 404413.

[31] Knowles RB, Park R. Strength of concrete filled steel tubular columns, Journal of the Structural Division ASCE 1969; 95(ST12): 2565-2587.

[32]Zhong S, Wang Y. Mechanical properties and design method of load-carrying capacity of CFST under compression (in Chinese). Journal of Harbin University of Civil Engineering and Architecture 1978; 1: 1-33.

[33]Pan Y, Liang JH. The effect of local welding on the behavior of concrete filled steel tubular columns under axial compression. Proceedings 2nd ASCCS International Conference on SteelConcrete Composite Structures. Harbin, China, 12-16 August 1988, 131-136.

[34] Gu W, Cai S, Feng W. Research on the behavior and load-carrying capacity of high-strength CFST columns under eccentric loading. Science of Construction (in Chinese) 1993; 3: 8-12.

[35] Matsui C, Tsuda K, Ishibashi Y. Slender concrete-filled steel tubular columns under combined compression and bending. Proceedings 4th Structural Steel Conference Singapore, 25-27 October 1995, 29-36.

[36] De Nardin S, El Debs ALH. Axial load behaviour of concrete-filled steel tubular columns. ICE. Structures \& Buildings 2007; 160: 13-22.

[37] Kilpatrick A, Rangan BV. Behavior of highstrength composite columns composite construction, conventional and innovative. Proceedings of the International Conference, Innsbruck, Austria, September 16-18, 1997, International Association of Bridge and
Structural Engineers, Lausanne, Switzerland, 789-794.

[38] Rangan BV, Joyce M. Strength of eccentrically loaded slender steel tubular columns filled with high-strength concrete. ACI Structural Journal 1992; 89(6): 676-681.

[39] Portolés JM, Romero ML, Bonet JL, Filippou FC. Experimental study of high strength concrete-filled circular tubular columns under eccentric loading. Journal of Constructional Steel Research 2011; 67(4): 623-633. 